\title{
Explosion Disaster Distribution Characteristics and Outlet Open-Close Effect of Turning Roadway
}

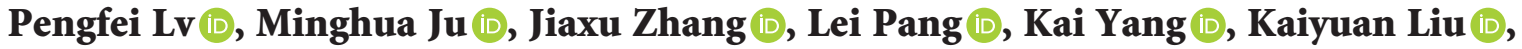 \\ and Mengyuan Liu $(\mathbb{D}$
}

Safety Engineering College, Beijing Institute of Petrochemical Technology, Beijing 102617, China

Correspondence should be addressed to Lei Pang; pang@bipt.edu.cn

Received 10 October 2020; Accepted 21 June 2021; Published 6 July 2021

Academic Editor: Jia-wen Zhou

Copyright (C) 2021 Pengfei Lv et al. This is an open access article distributed under the Creative Commons Attribution License, which permits unrestricted use, distribution, and reproduction in any medium, provided the original work is properly cited.

\begin{abstract}
In this study, under the open-close conditions of a roadway outlet, ANSYS/LS-DYNA was used to build models of explosions on roadways with $0^{\circ}$ and $90^{\circ}$ bending angles, to compare and analyze the shock wave propagation characteristics and variation laws. Combined with the damage degree classification of shock wave overpressure to human body, the destructive effect zoning of explosion in roadway under the condition of opening and closing of roadway entrance was studied. The results showed that as the bending angle increased, the peak overpressure attenuation of the shock waves became prominent, and the arrival time for the same distance increased. The closure of the roadway outlet had a distance effect on the peak overpressure of the shock waves. The explosion shock waves caused the peak overpressure to rise sharply owing to the reflection and stacking effects near the closure. In the far zone of the outlet, the attenuation of the shock waves was too fast and had minimal impact on the peak overpressure. In addition, the existence of the roadway closure increased the damage area and the severity of the blast wave to human body as a whole. With an increase in the bending angle, the damage range and severity decreased.
\end{abstract}

\section{Introduction}

An underground roadway is a typical underground confined space, where the characteristics of dynamite explosions differ greatly from those in an open space. Once an accidental explosion occurs in the roadway, the shock waves cannot quickly spread outward due to the restriction of the wall, thus increasing the overpressure duration and creating enormous threats for personnel and equipment. Worse still, any barrier in the roadway, or the closure of the outlet, could further intensify the reflection process and the damaging effects. The research on explosion shock waves in roadways is important not only for the evaluation of combat measures effectiveness, but also as a foundation for the analysis of accidental explosion system safety. Turning structures have been widely used in industrial, civil, and military roadway facilities; therefore, it is extremely necessary to study the distribution characteristics of explosion disasters, as well as the safety protection.
The most effective way to study the explosion shock waves process is to carry out explosive experiments. Dadone et al. [1] performed five types of tunnel experiments to study the pressure attenuation of shock waves passing through interaction points. The results showed that the pressure attenuation of shock waves at the interaction points could neglect the tunnel size effect. The calculation of the shock wave pressure changes near the interaction points, based on the steady flow pressure model, presented large errors. Savenk [2] studied the propagation characteristics and shock waves laws based on a model experiment. The attenuation coefficients of the shock waves passing through the local variation in bifurcation and turning were obtained. Limited by the research conditions, he was unable to perform indepth research in this field. Smith et al. [3] obtained the explosive point's overpressure time and propagation characteristics through explosion experiments in tunnels with different coarseness levels and loads. Britan et al. [4, 5] analyzed the effect of spheroidal particle filter parameters on 
shock wave attenuation. Based on the study of the change laws of shock waves passing through porous mediums with different geometric shapes and porosity, they proposed basic ideas of optimum underground space structural design. Pang et al. [6] conducted explosive experiments in tunnels with various turning angles and obtained the distribution law of a high-temperature flow field before and after the turning. Zhang et al. [7] studied the difference in the propagation velocity behavior of the detonation wave after large-scale diffraction and revealed the interaction mechanism between the diffraction wave and the detonation wave. Cheng et al. [8] proposed using a nonreactive gas jet $\left(\mathrm{CO}_{2}\right)$ to promote the formation of the precursor shock wave and the propagation speed of the flame in the deflagration wave and studied the effects of jet pressure and its position and jet parameters on the deflagration propagation.

Given the complexity of the explosion effects and difficult operation conditions, with the development of computer technology, numerical simulations can be used to study the explosive process. Given their low computational cost and wide range of data, numerical simulations had already been widely used [9-14]. Using simulations, Igra et al. [15] studied the shock waves' propagation characteristics in a $90^{\circ}$ branch pipe. The complicated, unsteady flow formed was affected by the shock waves and branch pipes. Rigas and Sklavounos [16] adopted computational fluid dynamics to analyze the shock waves' propagation in tunnels with complex geometrical shapes. The results indicated that the incident overpressure was far greater than the propagation overpressure. Luccioni et al. [17] put forward a grid size for explosive analysis, improving the precision of analyses. Ohtomo et al. [18] studied the propagation laws of shock waves passing through shock tunnels filled with inclined and staggered boards. The results showed that a shock wave attenuation occurred, and the effect was more obvious in shock tunnels filled with inclined boards. Berger et al. [19] investigated the impact of a single group of barriers and multiple groups of barriers on shock wave propagation characteristics in shock tunnels. The results revealed that, under the condition of large blocking rate, the geometrical shapes of the barriers play a key role in the shock wave attenuation. Zhao et al. [20] analyzed the structure strength and damage effect of a coal mine mobile refuge chamber under an explosion load. Zhang et al. [21, 22] used numerical simulation to study the explosion shock waves' peak pressure distribution when passing a $20^{\circ}, 45^{\circ}, 90^{\circ}$, and $135^{\circ}$ oneway turning roadway and revealed the influences of roadway geometry on the shock wave propagation laws. Additionally, the shock wave propagation laws in $45^{\circ}, 90^{\circ}, 135^{\circ}$, Y-shape, and $\mathrm{T}$-shape branched roadways were also simulated and studied.

The underground roadway system is complex, and there are often special structures such as cross-sectional area mutation, turning, bifurcation, and obstacles in the roadway. The air shock wave produced by underground blasting has great harm. It is of great significance to study the propagation law of air shock wave in the underground roadway system to control the harm of air shock wave. The results of previous studies showed that the research mainly focused on revealing the propagation law of air shock wave generated by explosives detonation in a small range, and the research mainly focused on straight roadways. Although some researchers had considered the impacts of roadway turning angle, geometric structure, and other factors, there were fewer studies on the shock wave propagation characteristics in complex underground roadway system such as continuous turning roadways. Furthermore, the open-close conditions of a roadway outlet's influence on shock wave propagation characteristics, and its destructive effect, were less researched. When the air shock wave propagated in the complex tunnel structure, the propagation law and damage effect were complex. This paper builds, through numerical simulation, and based on the roadway outlet's open-close conditions, respectively, models to analyze explosions in a roadway with $0^{\circ}$ and $90^{\circ}$ bending angles. The effect of the roadway outlet conditions on the shock wave propagation characteristics was analyzed. Additionally, the explosive destruction effect partition was analyzed based on the level of damage caused to the human body by the shock wave overpressure.

\section{Numerical Simulation}

2.1. Explosion Analysis Model. A nonlinear dynamic analysis finite element program called ANSYS/LS-DYNA was used to conduct a numerical simulation to study the open-close conditions of the influence of different turning roadway outlets on the explosion shock wave propagation characteristics. The bending angle between tangent line OA and straight line $\mathrm{OB}$ was marked as $\theta$, as shown in Figure 1(a). According to the value of $\theta$, two curved roadways with different curvatures were built, as shown in Figure 1(b). The bending angles were $0^{\circ}$ and $90^{\circ}$, respectively.

The simulated sectional dimension of the roadway was $3.5 \mathrm{~m} \times 3.5 \mathrm{~m}$, and the explosive source was located in the section core. The roadway with $\theta=0^{\circ}$ was taken as an example. Half of the three-dimensional explosion analysis models had been built according to symmetry, as seen in Figure 2. Figure 2(a) shows the model with the roadway outlet closure; that is, the roadway outlet was under a barrier sealing treatment. Figure 2(b) shows the model with the open roadway outlet. The horizontal length of the roadway was $100 \mathrm{~m}$, and the distance between the roadway outlet and the explosive source was also $100 \mathrm{~m}$.

To facilitate the analysis, the explosive source was taken as the origin of the coordinate system. Roadways with different curvatures were projected on the roadway with $\theta=0^{\circ}$. The vertical distance between the projection line and the explosive source was taken as the spacing, and the intersection of each projection line and the different curvature roadways were taken as survey points. Taking $10 \mathrm{~m}$ of spacing as an example, the roadway points with different curvatures were obtained, as shown in Figure 3.

2.2. Material Constitutive and State Equation. The numerical simulation analysis of the explosive issues played an important role in the study of the explosion mechanics. As an 


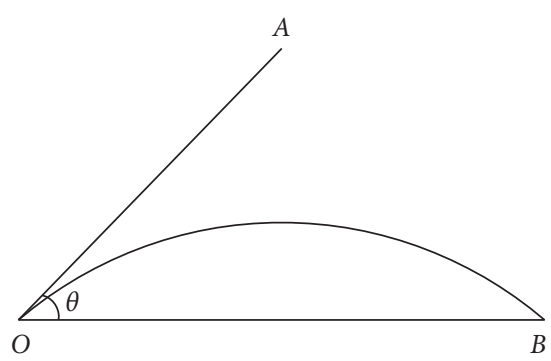

(a)

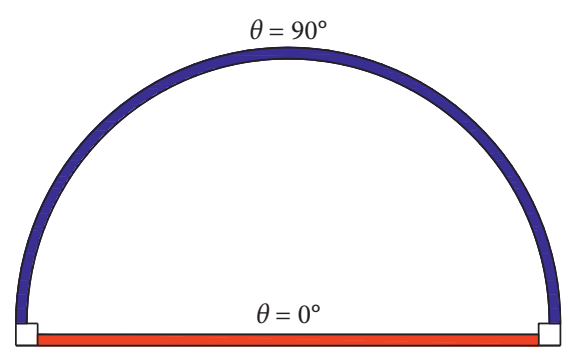

(b)

Figure 1: The bending angle and different curvature turning roadways. (a) Bending angle $\theta$. (b) Different curvature turning roadways.

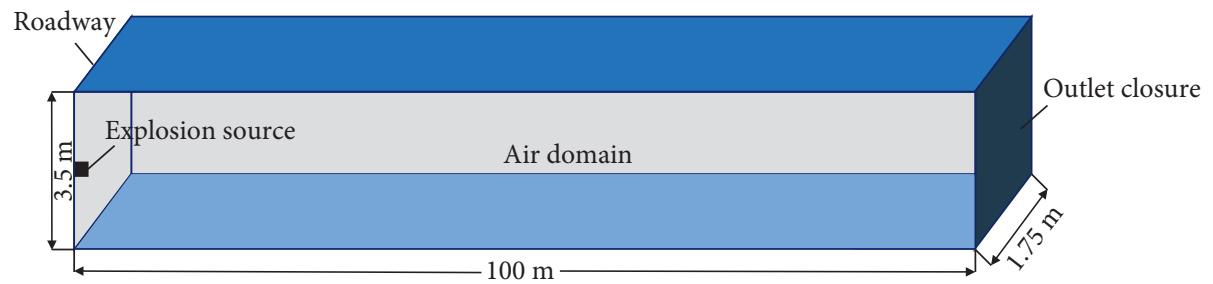

(a)

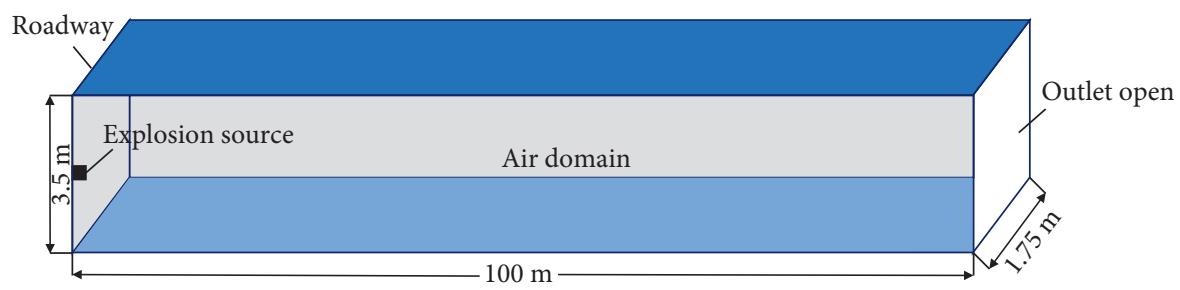

(b)

Figure 2: Explosion analysis model of roadway with $\theta=0^{\circ}$. (a) Outlet closure. (b) Outlet open.

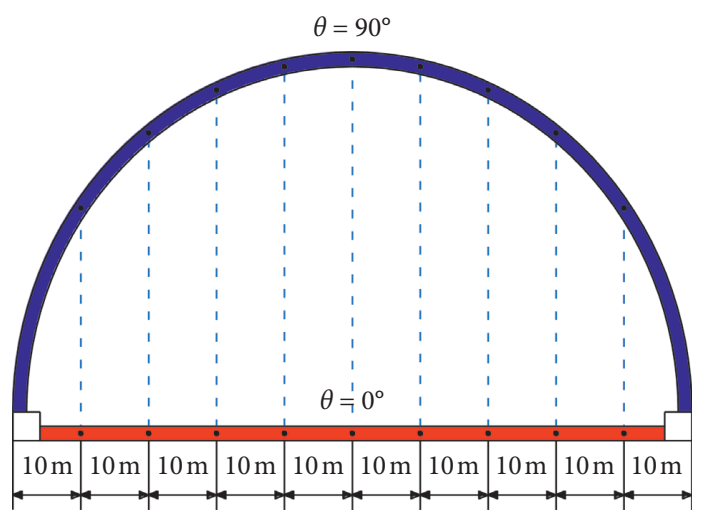

- Survey point

FIGURE 3: Survey point distribution in different curvature turning roadways.

effective tool for nonlinear impact dynamics analysis, the ANSYS/LS-DYNA software can effectively simulate the explosive process in various mediums, as well as different engineering blasting issues. The Lagrange and Euler algorithms were commonly used in numerical simulations. Among them, the Lagrange algorithm was often used to analyze problems involving solid mechanics, while the Euler algorithm was used more for fluid mechanics analysis. The explosion in different turning roadways was the interaction between the detonation gas and the solid walls, which was a typical fluid-structure interaction. Therefore, the ALE algorithm was adopted to solve the problem of large 
deformation calculations, combining the advantages of the Lagrange and Euler algorithms.

For an easier analysis, the explosive source was $5 \mathrm{Kg}$ TNT with a $1640 \mathrm{~kg} / \mathrm{m}^{3}$ charge density and $6930 \mathrm{~m} / \mathrm{s}$ explosive velocity. The explosive adopts the MAT_HIGH_EXPLOSIVE_BURN constitutive model provided by LS-DYNA. Given that the explosive gas exhibited substantial pressure fluctuations in the numerical simulation, ranging from hundreds of thousands of atmospheres to lower than one atmosphere, it was difficult to find the appropriate state equation of the explosion pressure variation range. JWL's [23] state equation is used in LS-DYNA to describe the relationship between the pressure and the volume variation of the detonation products. In JWL's state equation, the $\mathrm{P}-\mathrm{V}$ relationship is as follows:

$$
P=A\left(1-\frac{\omega}{R_{1} V}\right) e^{-R_{1} V}+B\left(1-\frac{\omega}{R_{2} V}\right) e^{-R_{2} V}+\frac{\omega E_{0}}{V},
$$

where $P$ refers to the pressure and $V$ refers to the volume. $E_{0}$ is the internal energy initial density. $A, B, R_{1}, R_{2}$, and $\omega$ are constants with values of $3.74,0.0743,4.1500001,0.95$, and 0.3 , respectively.

The air adopts the MAT_NULL material model provided by LS-DYNA. Its state equation can be expressed as follows:

$$
P=C_{0}+C_{1} \mu+C_{2} \mu^{2}+C_{3} \mu^{3}+\left(C_{4}+C_{5} \mu+C_{6} \mu^{2}\right) E,
$$

where $P$ is the instantaneous pressure and $\mu=\rho / \rho_{0}-1$, and $\rho / \rho 0$ is the ratio between the instantaneous density $\rho$ and the initial density $\rho_{0}$. The value of $\rho_{0}$ is $1.29 \mathrm{~kg} / \mathrm{m}^{3}$. E refers to the internal energy of a volume unit. $C_{0}-C_{6}$ are constants with values of $0,0,0,0,0.4,0.4$, and 0 , respectively.

The mechanical properties of the roadway wall affected the explosion shock waves. In real roadways, the materials were mainly solid rocks or concrete, whose intensities were far greater than the intensity of the shock waves obtained by numerical simulation. Therefore, the roadway walls could be viewed as rigid materials, and their structural damage and elastic deformation effects on the shock wave reflection and stacking process could be neglected.

\section{Results and Discussion}

3.1. Results Validation. The roadway with $\theta=0^{\circ}$ and open outlet was taken as an example to verify the reliability of the numerical simulation results. The shock wave peak overpressure in the unit of different positions was chosen as the study object. Subsequently, the shock wave overpressure and time changing curve were obtained, and the numerical simulation result was compared with the result obtained by Qin [24], as shown in Figure 4.

Figure 4 indicates that the numerical simulation result was consistent with the shock wave-overpressure/timevariation trend obtained by the empirical formula. Initially, the curve decreased sharply from the maximum, then changed slowly, and became stable. The maximum survey point error was $17 \mathrm{kPa}$, and the average error was $6 \mathrm{kPa}$. The two curves were extremely close, indicating the higher

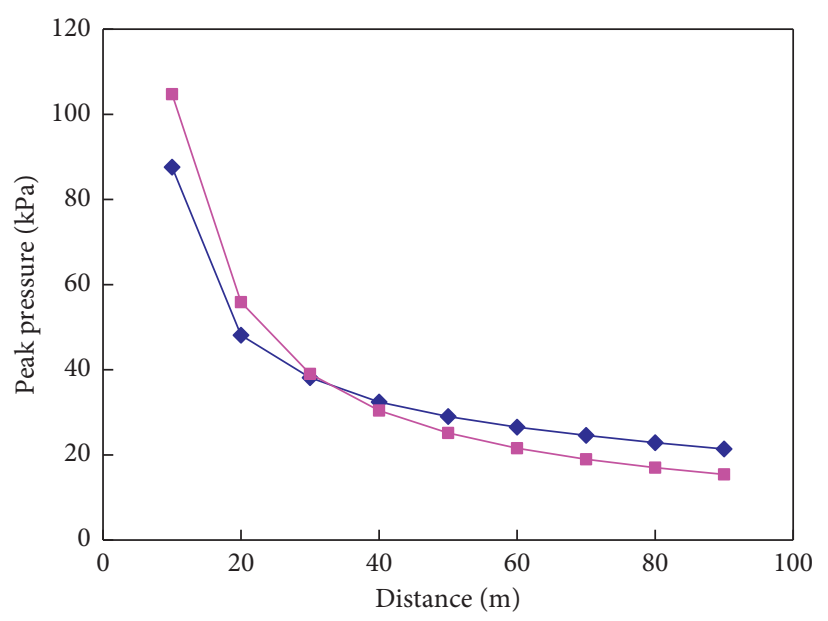

$\downarrow$ Numerical simulation results in this paper

$\rightarrow$ The formula results obtained by Qin (2008)

FIgURE 4: Comparison curves of peak pressure in roadway with $\theta=0^{\circ}$ under the condition of outlet open.

reliability and feasibility of the numerical simulation results presented herein.

\subsection{The Effect of Roadway Outlet Conditions on Distribution} of Shock Wave Peak Overpressure. In order to study the conditions of the roadway outlet's effect on the explosion shock waves, the air shock wave overpressures in different positions in the roadways with $0^{\circ}$ and $90^{\circ}$ blending angles were selected, to obtain the peak overpressure-distance distribution, as shown in Figure 5.

As seen in Figure 5, when $\theta=0^{\circ}$, the shock wave peak overpressure was essentially equal in the region of $0-80 \mathrm{~m}$ from the explosive source under the condition of roadway outlet closure and open. The roadway outlet closure had negligible impact on the shock wave peak overpressure. When the distance to the explosive source was $80-100 \mathrm{~m}$, and the roadway outlet was closed, the shock wave peak overpressure suddenly rose, showing an upward trend. In contrast, the shock wave peak overpressure decreased gradually when the roadway outlet was open. When $\theta=90^{\circ}$, the peak overpressure distribution had similar features but differed in different regions; that is, when the distance to the explosive source was between $0 \mathrm{~m}$ and $90 \mathrm{~m}$, the shock wave peak overpressure was essentially equal to that of the condition of roadway outlet closure and open. When the distance was between $90 \mathrm{~m}$ and $100 \mathrm{~m}$, the shock wave peak overpressure increased under the condition of roadway outlet closure and reduced with the outlet open. The analysis showed that when the exit of the roadway was open, the energy was released instantly after the explosion source detonated, and the pressure of the explosion shock wave reached the peak value near the explosion source. Then, due to the influence of the frictional resistance of the roadway wall and the loss of energy transferred in the air flow, the peak overpressure in the roadway showed a trend of attenuation with the increase of the distance from the explosion source. When the roadway exit was closed, the peak 


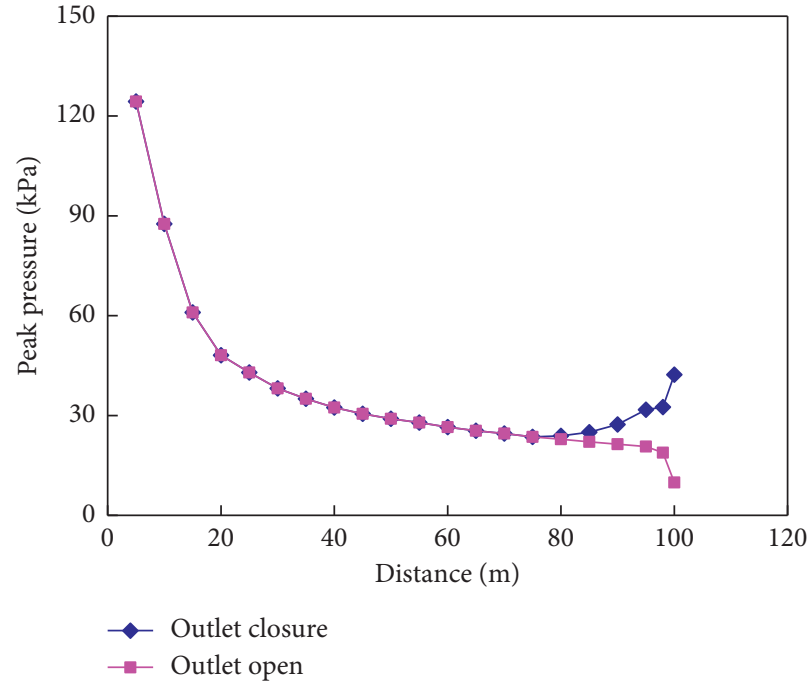

(a)

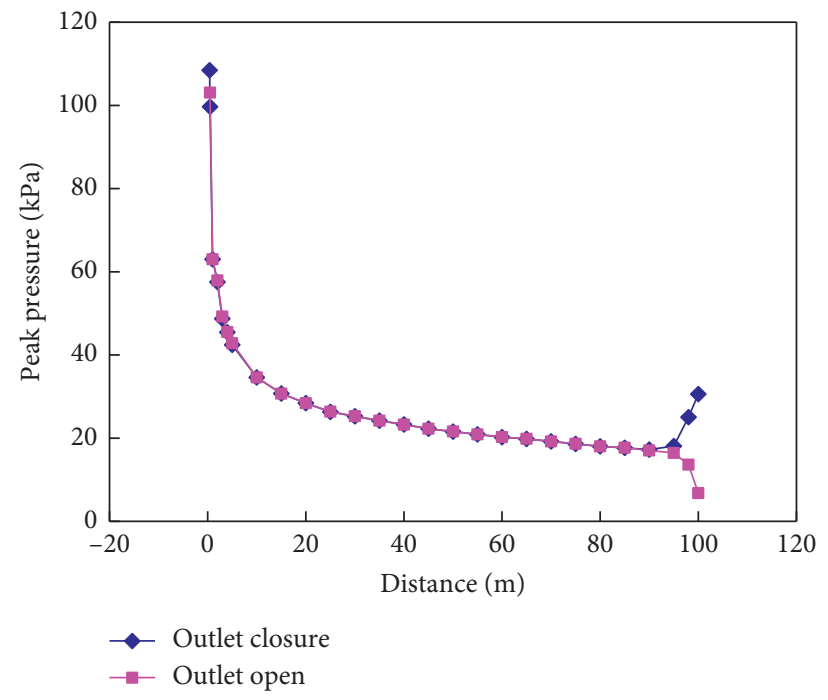

(b)

Figure 5: Peak pressure distribution in different curvature turning roadways. (a) $\theta=0^{\circ}$. (b) $\theta=90^{\circ}$.

overpressure increased due to the reflection and superposition of the explosion shock wave by the obstacles near the roadway exit, causing the peak overpressure curve to first decrease and then increase. When $\theta=90^{\circ}$, the peak overpressure curve was lower than that when $\theta=0^{\circ}$. This was related to the attenuation caused by the refraction and reflection of the shock wave on the wall at the corner of the roadway.

To further study the effect of the roadway outlet conditions on the explosion shock wave overpressure distribution in different turning roadways and regions, when $\theta=0^{\circ}$, the roadway was divided into two zones by an $80 \mathrm{~m}$ distance to the explosive source as the boundary; that is, one zone was between $10 \mathrm{~m}$ and $70 \mathrm{~m}$, and the other zone was between $80 \mathrm{~m}$ and $100 \mathrm{~m}$. When $\theta=90^{\circ}$, the roadway was divided into two zones by a $90 \mathrm{~m}$ distance to explosive source as the boundary, that is, a $10-80 \mathrm{~m}$ zone, and a $90-100 \mathrm{~m}$ zone. Subsequently, the corresponding explosion shock wave overpressure and time distribution curves were obtained, under the condition of roadway outlet closure and open, as shown in Figures 6 and 7.

As seen in Figures 6(a), 6(b), 7(a), and 7(b), when the roadway outlet was closed, the time changing curves of the shock wave overpressure in different positions were similar. Initially, the peak pressure increased from zero to the maximum sharply, then decreased rapidly, and continued to decay, increased again to peak, and then began to decay. There were two peak values except at the outlet position. One was formed by shock waves passing through different positions after the explosion. The other was formed when the shock waves pass the barriers at the outlet, where only one peak was formed after the stacking of two peaks, and the peak pressure was considerably greater than the second peak pressure in other observation points. Furthermore, the comparison between Figures 6(a), 7(a), 6(b), and 7(b) indicated that the peak pressure when $\theta=90^{\circ}$ decreased, and the arrival time to the same distance increased, compared with those when $\theta=0^{\circ}$. Under the condition of outlet closure, two peak overpressures were chosen to obtain their distribution curves in different turning roadways, as seen in Figure 8.

In Figures $8(\mathrm{a})$ and $8(\mathrm{~b})$, the first peak overpressure overall decreased (excluding at the outlet points) with the increase in the propagation distance, while the second peak overpressure showed opposite characteristics, with the peak overpressure rising gradually as the propagation distance increased, especially at the outlet, where the peak overpressure reached its maximum. These analyses suggested that when the outlet was closed, the explosion shock waves had little effect on peak overpressure in the far zone of outlet, due to the shock waves decreasing greatly after the barriers' reflection away from the outlet. While the explosion shock waves reflection and stacking effects caused peak overpressure to increase in the outlet near zone, the maximum peak pressure was formed in the curve. It can be seen that the closed condition of the roadway had a distance effect on the shock wave peak overpressure in the roadway.

Based on Figures 6(c), 6(d), 7(c), and 7(d), when the roadway outlet was open, the variation curves of the shock wave overpressure in different positions would increase from zero to peak and then begin to reduce sharply. In contrast, when the roadway was closed, the pressure curves peak was formed only once. Moreover, the shock wave peak overpressure decreased with the increase in the propagation distance. Furthermore, the comparison between Figures 6(c), 7(c), 6(d), and $7(\mathrm{~d})$ indicated that as the $\theta$ bending angle of the roadway increased, the peak overpressure at the same distance decreased continuously, and the arrival time to the same distance increased. Therefore, the bending angle can change the space-time distribution of the shock wave overpressure in the roadway.

This section studied the influence of the closed and open state of the roadway exit on the explosion shock wave in the roadway. The conditions of the roadway exit were simulated 


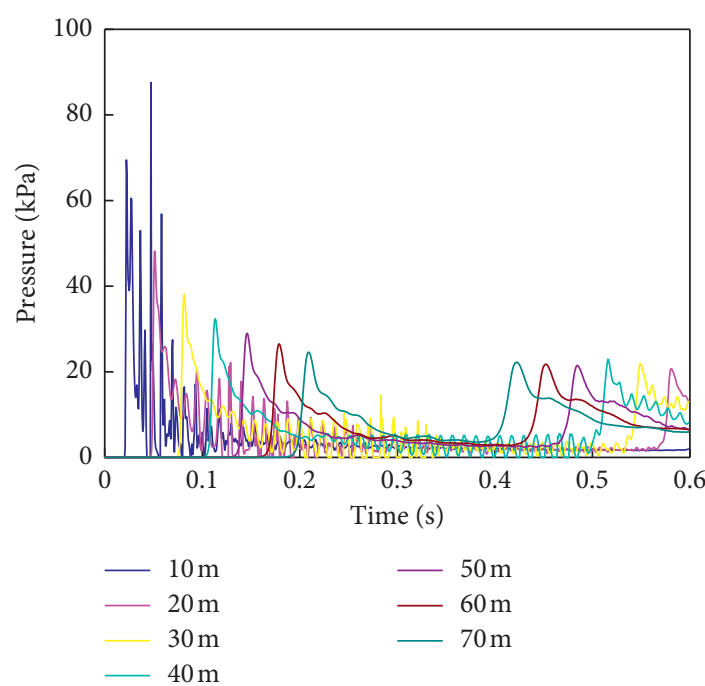

(a)

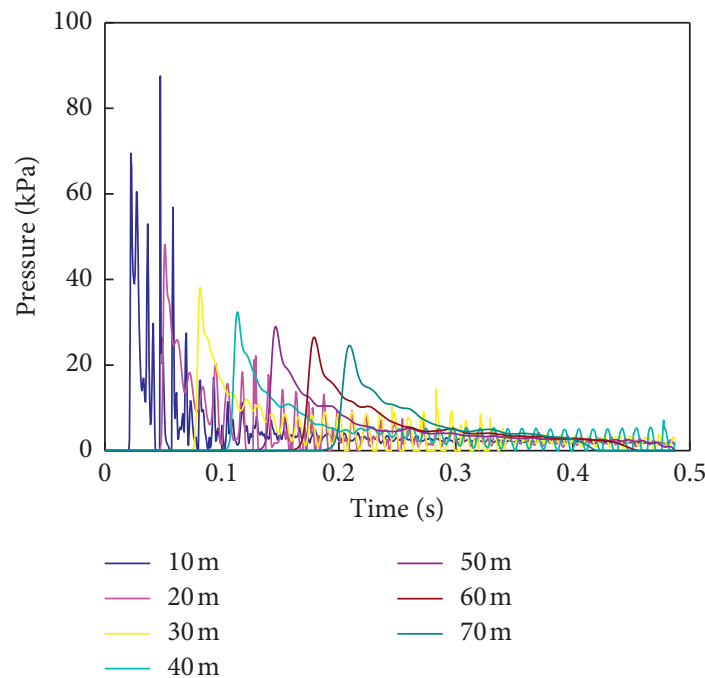

(c)

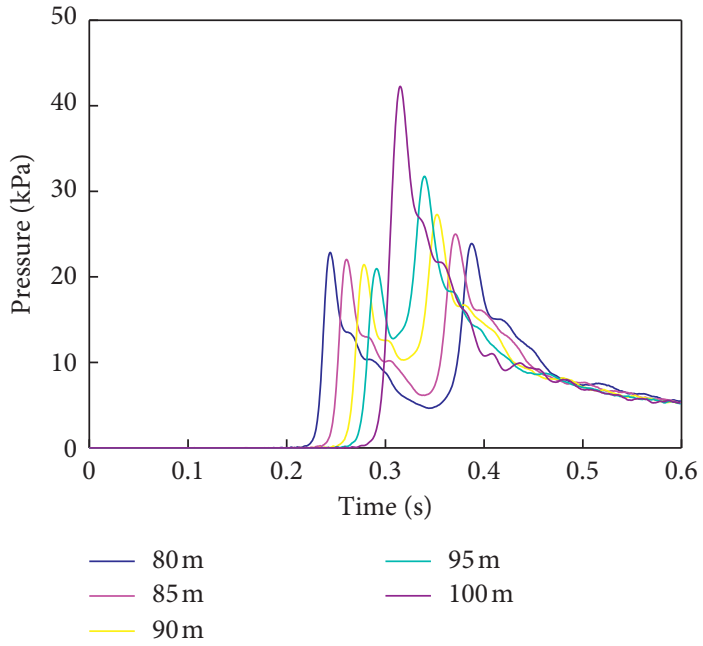

(b)

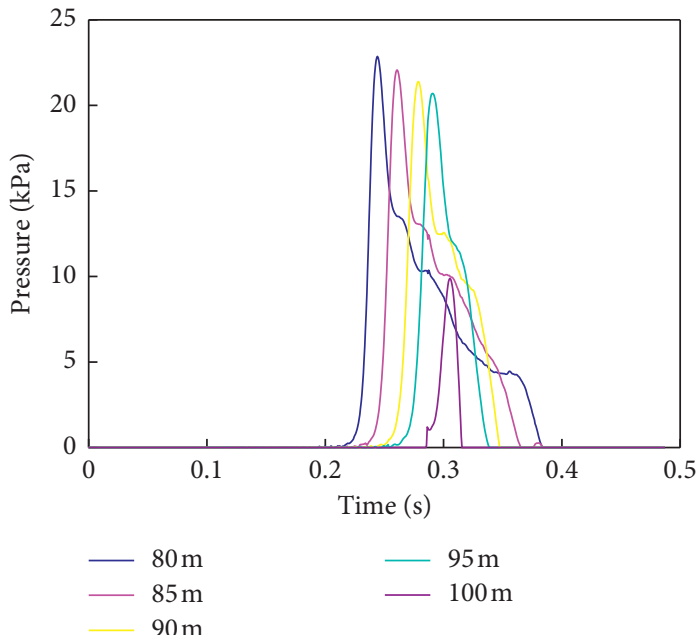

(d)

Figure 6: Pressure distribution in roadway with $\theta=0^{\circ}$. (a) $10 \sim 70 \mathrm{~m}$ zone with outlet closure. (b) $80 \sim 100 \mathrm{~m}$ zone with outlet closure. (c) $10 \sim 70 \mathrm{~m}$ zone with outlet open. (d) $80 \sim 100 \mathrm{~m}$ zone with outlet open.

and set as open and closed, and the turning angles were $0^{\circ}$ and $90^{\circ}$. The change law of blast wave in roadway was obtained, and the reason was preliminarily analyzed. However, due to the lack of cloud images related to shock waves, it was impossible to observe the changes of shock waves in the roadway directly. Therefore, the next step will be to improve the relevant research in order to more intuitively analyze the reflection and diffraction of shock waves in the roadway.

3.3. The Influence of Roadway Outlet Conditions on Explosive Destructive Effect Partition. Based on the explosion shock wave overpressure's level of injury to the human body shown in Table 1 [25], when the shock wave overpressure was more than $100 \mathrm{kPa}$ in the explosion-affected zone, the zone would be regarded as the dead zone (marked by Zone A). When the shock wave overpressure was between $50 \mathrm{kPa}$ and $100 \mathrm{kPa}$, the zone would be considered as a serious damage zone (marked by Zone B). When the shock wave overpressure was between $30 \mathrm{kPa}$ and $50 \mathrm{kPa}$, the zone was identified as a moderate damage zone (marked by Zone $\mathrm{C}$ ). When the shock wave overpressure was between $20 \mathrm{kPa}$ and $30 \mathrm{kPa}$, the zone was determined as a slight damage zone (marked by Zone D). When the shock wave overpressure was between $0 \mathrm{kPa}$ and $20 \mathrm{kPa}$, the zone was determined as a no damage zone (marked by Zone E). Combined with the numerical simulation results, Figures 9 and 10 show the explosive destruction effect partition in the roadways with $0^{\circ}$ and $90^{\circ}$ bending angles, under the condition of roadway outlet closure and open. Table 2 shows each zone range for different curvature turning roadways, based on the explosive destruction effect partition.

In Figure 9 and Table 2, when the outlet of the roadway with $0^{\circ}$ bending angle was closed, zones $\mathrm{A}, \mathrm{B}, \mathrm{C}$, and $\mathrm{D}$ were formed in the roadway after the explosion. When the 

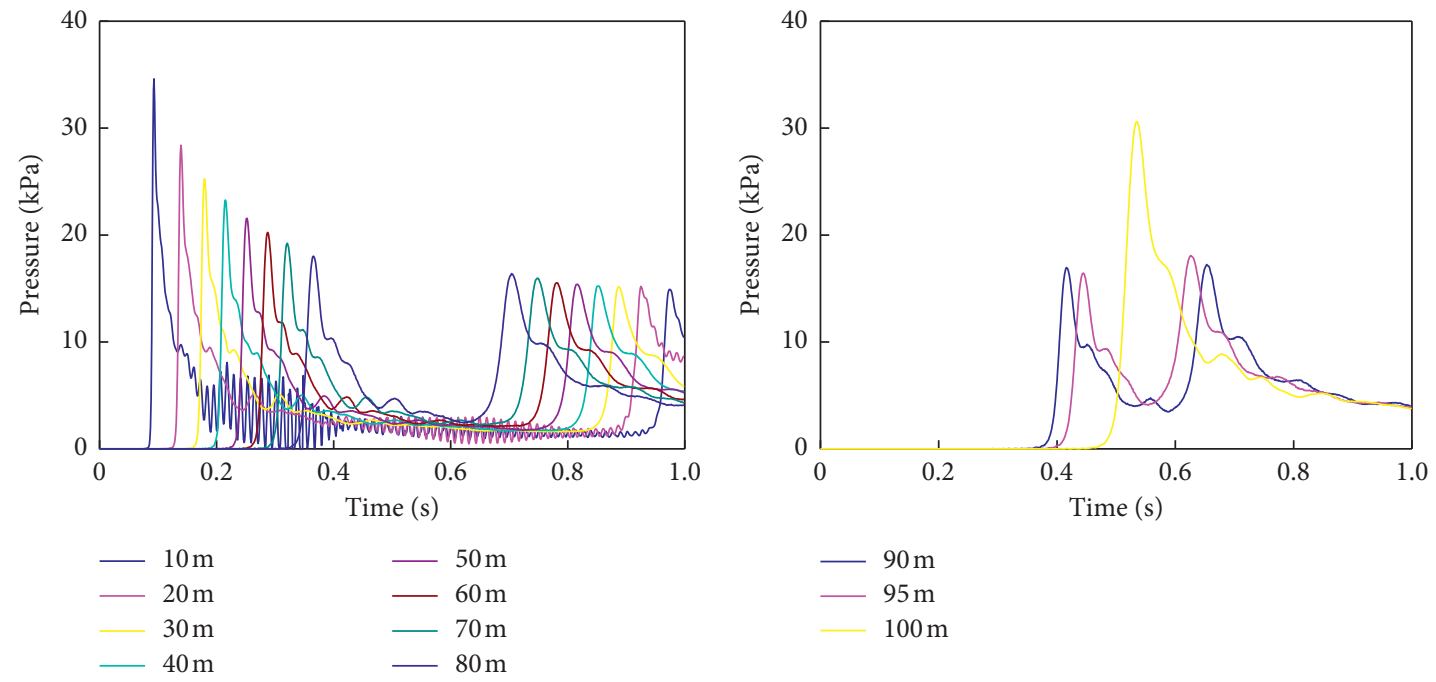

(a)

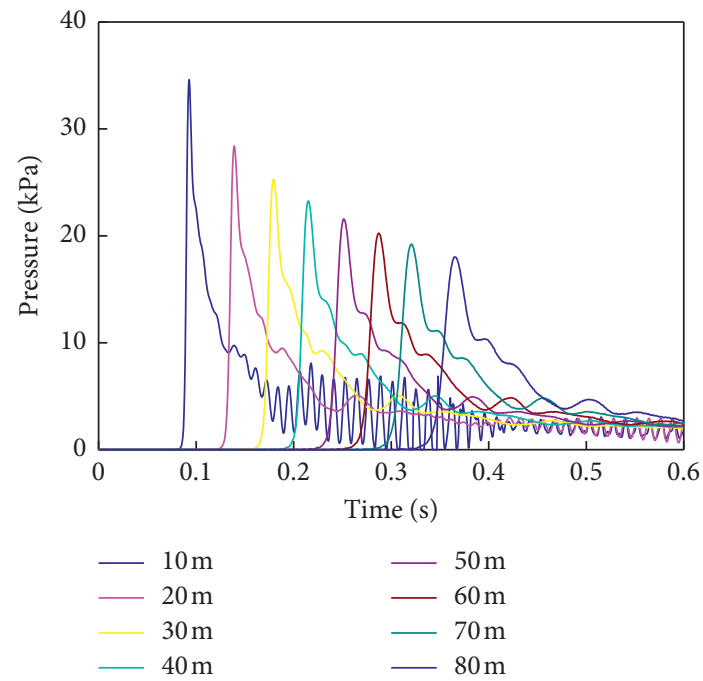

(b)

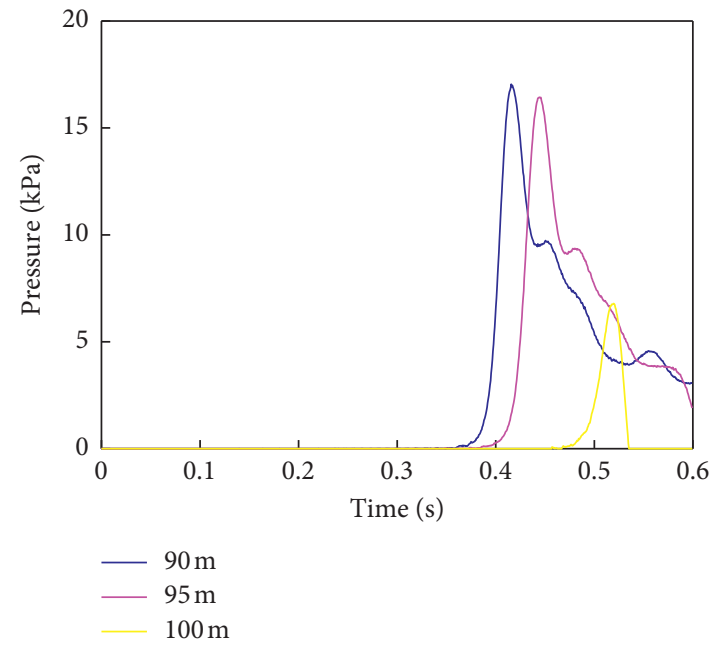

(c)

(d)

FIGURe 7: Pressure distribution in roadway with $\theta=90^{\circ}$. (a) $10 \sim 80 \mathrm{~m}$ zone with outlet closure. (b) $90 \sim 100 \mathrm{~m}$ zone with outlet closure. (c) 10 80 m zone with outlet open. (d) $90 \sim 100 \mathrm{~m}$ zone with outlet open.

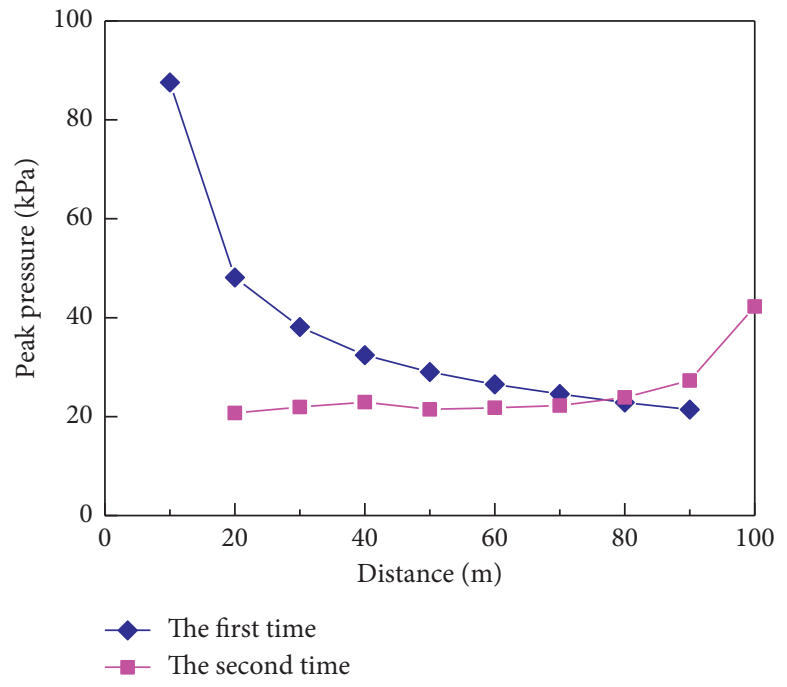

(a)

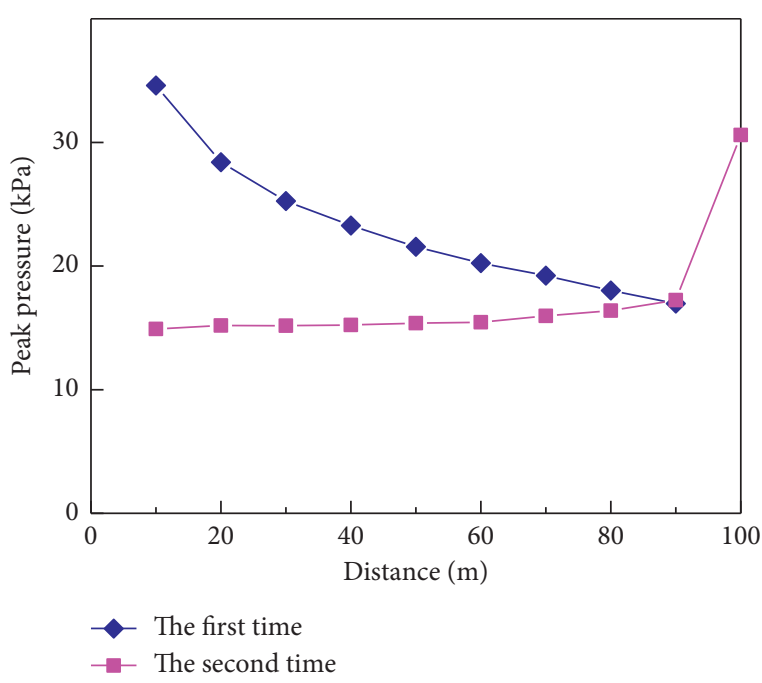

(b)

FIGURE 8: Peak pressure distribution in roadway of different curvature turning roadways with outlet closure. 
TABLE 1: Explosion shock wave overpressure' level of injury to human body.

\begin{tabular}{lc}
\hline Overpressure $(\mathrm{kPa})$ & Injury effect \\
\hline$<20$ & No injuries but be scared \\
$20 \sim 30$ & Minor injury \\
$30 \sim 50$ & Hearing organ injury or fracture \\
$50 \sim 100$ & Severe visceral injury or death \\
$>100$ & The majority of deaths \\
\hline
\end{tabular}

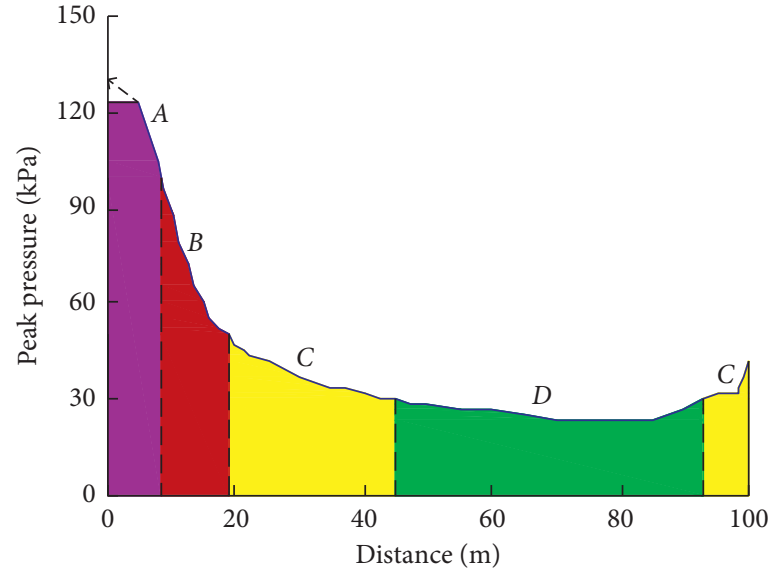

(a)

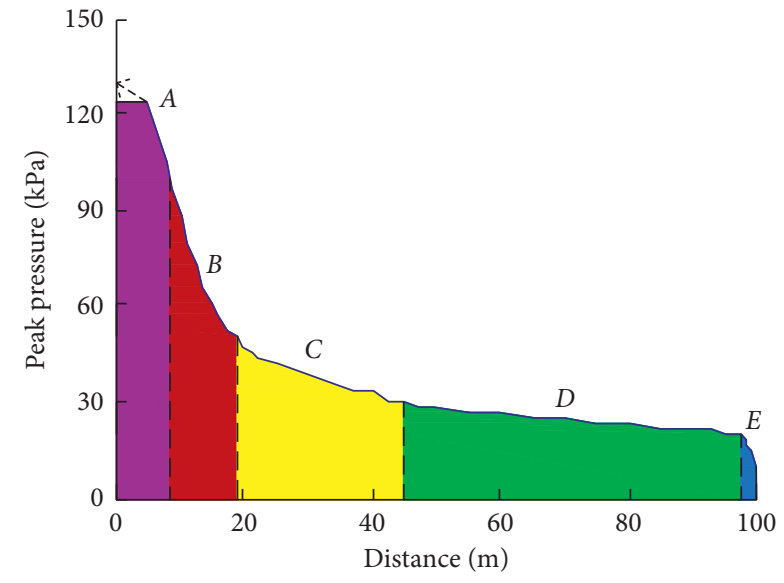

(b)

Figure 9: Explosive destruction effect partition in roadway with $\theta=0^{\circ}$. (a) Outlet closure. (b) Outlet open.

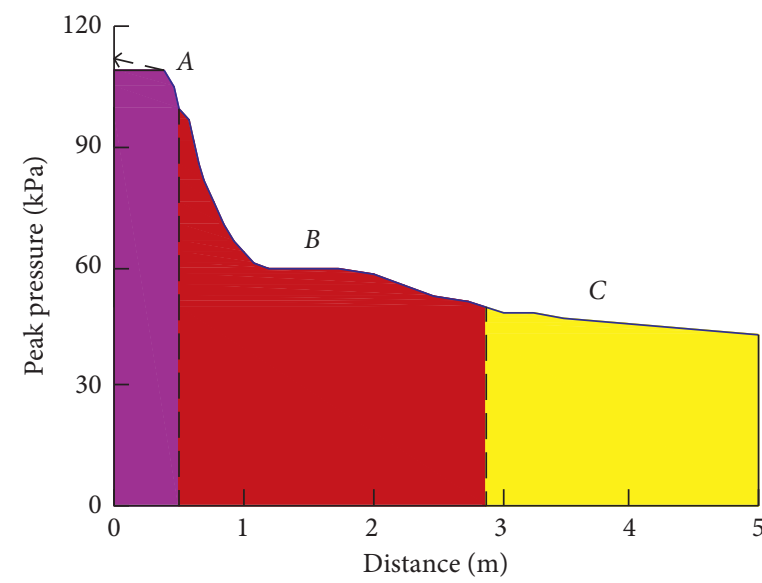

(a)

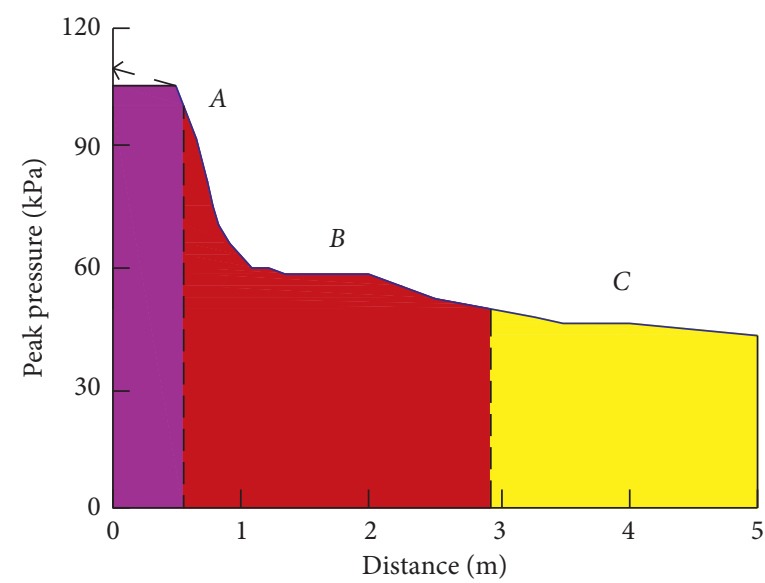

(c)

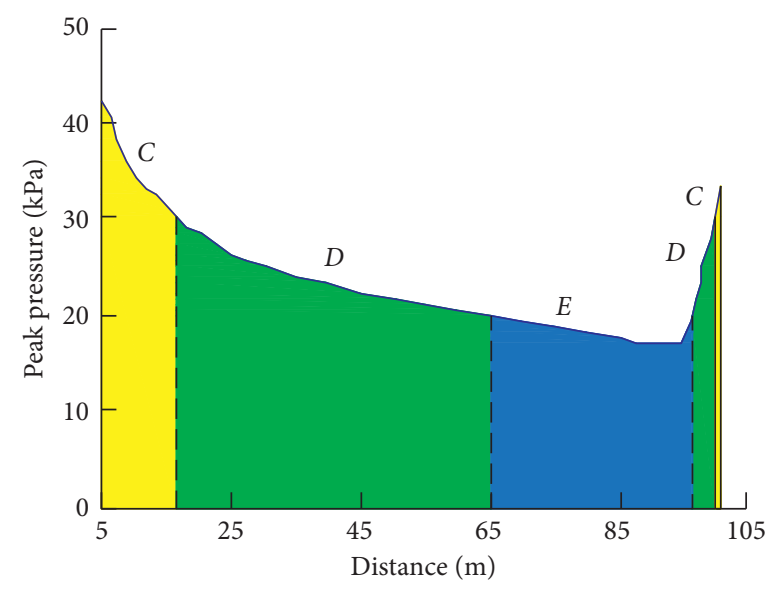

(b)

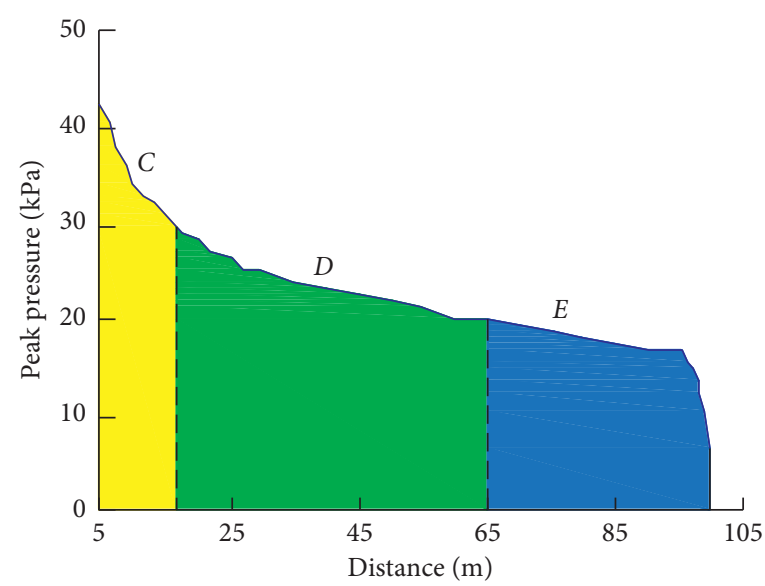

(d)

FIGURe 10: Explosive destruction effect partition in roadway with $\theta=90^{\circ}$. (a) With outlet closure (0-5 m). (b) With outlet closure (5-100 m). (c) $0 \sim 5 \mathrm{~m}$ zone with outlet open. (d) $5 \sim 100 \mathrm{~m}$ zone with outlet open. 
TABLE 2: Range of explosive destruction effect partition of different curvature turning roadways.

\begin{tabular}{ccccccc}
\hline \multirow{2}{*}{ Roadway type } & \multicolumn{4}{c}{ Explosion damage range $(\mathrm{m})$} \\
& Zone A & Zone B & Zone C & Zone D & Zone E \\
\hline \multirow{2}{*}{$\theta=0^{\circ}$} & With outlet closure & $(0,8.64)$ & $(8.64,18.94)$ & $(18.94,44.7),(93.18,100)$ & $(44.7,93.18)$ \\
& With outlet open & $(0,8.44)$ & $(8.44,18.8)$ & $(18.8,47.37)$ & $(47.37,96.24)$ & $(96.24,100)$ \\
\hline \multirow{2}{*}{$\theta=90^{\circ}$} & With outlet closure & $(0,0.5)$ & $(0.5,2.87)$ & $(2.87,16.54),(99.46,100)$ & $(16.54,65),(95.96,99.46)$ & $(65,95.96)$ \\
& With outlet open & $(0,0.55)$ & $(0.55,2.96)$ & $(2.96,16.44)$ & $(16.44,65.33)$ & $(65.33,100)$ \\
\hline
\end{tabular}

roadway outlet was open, zones $\mathrm{A}, \mathrm{B}, \mathrm{C}, \mathrm{D}$, and $\mathrm{E}$ were formed. Comparing between the range of zones when the roadway outlet was closed and open, the ranges of zones $\mathrm{A}$ (dead zone) and B (serious damage zone) were essentially the same. When the roadway outlet was closed, zone $\mathrm{C}$ (moderate damage zone) range increased visibly and caused zone D (slight damage zone) range to move forward.

In Figure 10 and Table 2, when the outlet of the roadway with a $90^{\circ}$ bending angle was closed, zones $\mathrm{A}, \mathrm{B}, \mathrm{C}, \mathrm{D}$, and $\mathrm{E}$ were formed in the roadway after explosion. Comparing between the range of zones with the open and closed outlet, the ranges of zone A (dead zone) and zone B (serious damage zone) were essentially equal. However, when the outlet was closed, zone $\mathrm{C}$ (moderate damage zone) and zone $\mathrm{D}$ (slight damage zone) ranges increased visibly, and zone $\mathrm{E}$ (no damage zone) range decreased.

Overall, the closure of the roadway outlet increased the damage range of the explosion shock waves and the severity of their impact on the human body. In addition, when the roadway outlet was closed, and the bending angle of the roadway was $0^{\circ}$, the ranges from $\mathrm{A}$ to $\mathrm{C}$ were clearly larger than the corresponding ranges when the bending angle was $90^{\circ}$. Zone D (slight damage zone) and zone $\mathrm{E}$ (no damage zone) ranges decreased visibly, indicating that the damage range and severity decreased with the increase in the roadway bending angle.

In this section, combined with the results of numerical simulations, the partitions were classified according to the degree of damage caused by the shock wave overpressure to the human body under the explosion conditions, and the partition of the explosion damage effect in the roadway at $\theta=0^{\circ}$ and $\theta=90^{\circ}$ under the closed and open conditions of the roadway exit was obtained. Comparing the results of the partitions under the two bending angles, it was found that the closed state of the roadway exit increased the damage area and the severity of the damage caused by the explosion shock wave to the human body as a whole, and as the bending angle of the roadway increased, the damage range and the severity of the damage decreased. Because the bending angle interval of the two roadways was too large, there was a lack of research on the damage effect of different bending angles between them. The next step will be to refine the bending angle interval and study the change law of its damage degree and damage range.

\section{Conclusions}

The bending angle can change the space-time distribution of the explosion shock waves in the roadway. As the roadway bending angle increased, the shock wave peak overpressure attenuation was obvious, and the arrival time to the same distance was increasing. When the roadway outlet was closed, the explosion shock waves would cause the peak overpressure to rise sharply after the reflection and stacking effects in the near zone of the outlet. In the far zone of the outlet, the shock wave effects on peak overpressure were lighter due to the rapid attenuation after reflection. Therefore, the closure of the roadway outlet had a distance effect on the shock wave peak overpressure.

According to the level of injury to the human body caused by the explosion shock wave overpressure, the explosion-affected zones in the roadway can be classified into dead zones, serious damage zones, moderate damage zones, slight damage zones, and no damage zones. The increase in the bending angle can, overall, reduce the explosive damage range and severity. However, the closure of the roadway outlet can, overall, increase the explosive damage range and severity. It can be seen that the bending angle and outlet conditions affect the distribution characteristics of the explosion disaster in the turning roadway. This research can provide a reference for explosion disaster evaluation and accident analysis in roadways.

\section{Data Availability}

The data used to support the findings of this study are available from the corresponding author upon request.

\section{Conflicts of Interest}

The authors declare that there are no conflicts of interest regarding the publication of this paper.

\section{Acknowledgments}

The authors thank the financial support of the National Nature Science Foundation of China (Grant no. 51604031), the Supporting Plan for the Construction of High-Level Teachers in Beijing Universities in 2019 (Grant no. CIT\&TCD201904045), the Key Technology Project of Safety Production in 2017 of China (Grant no. Beijing-00072017AQ), and the Beijing Natural Science Foundation Municipal Education Committee Joint Funding Project (Grant no. KZ201910017020). Meanwhile, the authors thank English translation service provided by Beijing T-norm Translation Service Co., Ltd, and thank Elsevier for retouching the language. 


\section{References}

[1] A. Dadone, M. Pandolfi, and F. Tamanini, "Shock waves propagating in a straight duct with aside branch," in Proceedings of the 8th International Shock Tube Symposium, London, UK, July 1971.

[2] C. K. Savenk, Air Shock Wave in Tunnel under Mine, Metal Industry Press, Beijing, China, 1979.

[3] P. D. Smith, G. C. Mays, T. A. Rose et al., "Small scale models of complex geometry for blast overpressure assessment," International Journal of Impact Engineering, vol. 12, no. 3, pp. 345-360, 1992.

[4] A. Britan, G. Ben-Dor, O. Igra, and H. Shapiro, "Shock waves attenuation by granular filters," International Journal of Multiphase Flow, vol. 27, no. 4, pp. 617-634, 2001.

[5] A. Britan, O. Igra, G. Ben-Dor, and H. Shapiro, "Shock wave attenuation by grids and orifice plates," Shock Waves, vol. 16, pp. 1-15, 2006.

[6] L. Pang, J. C. Gao, Q. J. Ma et al., "Influence of bend structure on high-temperature flow after gas explosion," Experimental Thermal and Fluid Science, vol. 49, pp. 201-205, 2013.

[7] B. Zhang, H. Liu, and B. J. Yan, "Velocity behavior downstream of perforated plates with large blockage ratio for unstable and stable detonations," Aerospace Science and Technology, vol. 86, pp. 236-243, 2019.

[8] J. Cheng, B. Zhang, H. Liu, and F. Wang, "The precursor shock wave and flame propagation enhancement by $\mathrm{CO}_{2}$ injection in a methane-oxygen mixture," Fuel, vol. 283, Article ID 118917, 2021.

[9] A. M. Benselama, M. J.-P. William-Louis, F. Monnoyer, and C. Proust, "A numerical study of the evolution of the blast wave shape in tunnels," Journal of Hazardous Materials, vol. 181, pp. 609-616, 2010.

[10] P. C. Chan and H. H. Klein, "A study of blast effects inside an enclosure," Journal of Fluids Engineering, vol. 116, pp. 450455, 1994.

[11] B. Janovsky, P. Selesovsky, J. Horkel, and L. Vejsa, "Vented confined explosions in Stramberk experimental mine and autoreagas simulation," Journal of Loss Prevention in the Process Industries, vol. 19, pp. 280-287, 2006.

[12] Y. Sugiyama, T. Homae, K. Wakabayashi, T. Matsumura, and Y. Nakayama, "Numerical simulations on the attenuation effect of a barrier material on a blast wave," Journal of Loss Prevention in the Process Industries, vol. 32, pp. 135-143, 2014.

[13] C. Wang, W. H. Han, J. G. Ning, and Y. Yang, "High resolution numerical simulation of methane explosion in bend ducts," Safety Science, vol. 50, no. 4, pp. 709-717, 2012.

[14] G. H. Wang, Y. X. Wang, W. B. Lu, W. Zhou, M. Chen, and P. Yan, "On the determination of the mesh size for numerical simulations of shock wave propagation in near field underwater explosion," Applied Ocean Research, vol. 59, pp. 1-9, 2016.

[15] O. Igra, L. Wang, J. Falcovitz, and W. Heilig, "Shock wave propagation in a branched duct," Shock Waves, vol. 8, pp. 375-381, 1998.

[16] F. Rigas and S. Sklavounos, "Experimentally validated 3-D simulation of shock waves generated by dense explosives in confined complex geometries," Journal of Hazardous Materials, vol. 121, pp. 23-30, 2005.

[17] B. Luccioni, D. Ambrosini, and R. Danesi, "Blast load assessment using hydrocodes," Engineering Structures, vol. 28, no. 12, pp. 1736-1744, 2006.
[18] F. Ohtomo, K. Ohtani, and K. Takayama, "Attenuation of shock waves propagating over arrayed baffle plates," Shock Waves, vol. 14, pp. 379-390, 2005.

[19] S. Berger, O. Sadot, and G. Ben-Dor, "Experimental investigation on the shock-wave load attenuation by geometrical means," Shock Waves, vol. 20, pp. 29-40, 2010.

[20] H. J. Zhao, X. M. Qian, and J. Li, "Simulation analysis on structure safety of coal mine mobile refuge chamber under explosion load," Safety Science, vol. 50, no. 4, pp. 674-678, 2012.

[21] Q. Zhang, B. Qin, and D. C. Lin, "Estimation of pressure distribution for shock wave through the bend of bend laneway," Safety Science, vol. 48, no. 10, pp. 1263-1268, 2010.

[22] Q. Zhang, B. Qin, and D. C. Lin, "Estimation of pressure distribution for shock wave through the junction of branch gallery," Safety Science, vol. 57, pp. 214-222, 2013.

[23] Lstc, LSDYNA. User's Manual, Livermore Software Technology Corporation, Livermore, CA, USA, 2003.

[24] B. Qin, "Research on shock wave propagating characteristic and rules inside the complex underground tunnels," Ph.D. thesis, Beijing Institute of Technology, Beijing, China, 2008.

[25] Y. C. Gu, Y. Y. Shi, and J. L. Jin, Engineering Blasting Safety, Press of University of Science and Technology of China, Hefei, China, 2009. 